\title{
THE POTENTIAL OF PARTICIPATORY DESIGN TO IMPROVE URBAN SPACES IN THE SLUMS OF CARACAS, VENEZUELA
}

\author{
CARLOS E. GONZALEZ R., PRASANNA DIVIGALPITIYA \& TAKERU SAKAI \\ Laboratory of Urban Planning, Department of Architecture, Kyushu University, Japan
}

\begin{abstract}
It may be said that slums have become one with Caracas, and so to eradicate them completely would be almost impossible task. A more suitable solution therefore is to rehabilitate these areas, and improve the current living environment. Taking into account the meagre access to construction materials, the prevailing social conditions, and the absence of appropriate planning, we studied the potential of involving the inhabitants themselves through Participatory Development. After a detailed analysis of the current urban spaces, and following consultation of the local community, as well as professionals working in this field, we are able to generate lists of priorities based directly on the local inhabitants' needs and desires, including: playgrounds; pathways; green areas; community centres; and other forms of small to medium-scale projects. This forms the basis for developing proposals to improve their community with their involvement and assistance. As was the case with urban projects such as 'Espacios de Paz' and 'Inclusión de Habitantes' (which included aspects of Slum Upgrading strategies and Participatory Design in slums of Venezuela), we conclude that shifting the methodology from slum eviction to slum upgrading fosters inclusion and respect for local heritage and culture, and creates a more sustainable and human-focused approach that aims to provide solutions to an on-going, deepseated challenge.

Keywords: urban poverty, participatory development, informal settlements, slum rehabilitation.
\end{abstract}

\section{INTRODUCTION}

Slums and other forms of informal settlements are undoubtedly one of the most pressing issues facing architects, planners, and governments in countries where, given their respective natural, economic or political circumstances, the housing supply and appropriate planning haven't managed to meet the needs of their inhabitants. This has become a very substantial setback in developing nations such as India, South Africa, and Brazil, where despite their growing economies and best efforts, the growth of slums continues to eclipse social and structural urban improvements [1].

The UN-Habitat defines slums as having five specific characteristics: "inadequate access to safe water, inadequate access to sanitation and infrastructure, poor structural quality of housing, overcrowding, insecure residential status" [2]. These informal settlements are often located in peri-urban areas of the city (outskirts), where housing units are built in a disorderly fashion, that is to say, without construction permits or any kind of authority regulations that could control aspects such as quality and safety. This does, at times, lead to uncontrollable developments that shape the urban morphology as we know it, generating a wide range of both social and spatial complications.

It is estimated that about $33 \%$ of the world's population ( 863 million people) is currently living in precarious settlements, where there are, in many cases, alarming levels of delinquency - often linked to poor access to education [3]. One of the main reasons why such settlements have formed, and why people continue to move to, and live in them is because of their proximity to better developed urban areas, which grants them access to more work opportunities; although since most of these individuals will not be qualified for professional jobs, their income is often not enough to extricate them from their status of poverty. Another 
important factor to take into account is the better access to sanitation infrastructure and healthcare facilities in fully or partially developed cities when compared to more rural areas in third-world countries, where these are often absent, spread out, inconvenient or insufficient.

In Latin America, urban poverty is a very present reality, and resulting patterns of geographical, racial, economical, and educational exclusion can be witnessed across the major cities. Mexico, with a total population of 130 million people, has what is considered to be one of the largest slums in the world, the Neza-Chalco-Itza in Mexico City, with an approximate population of 4 million residents. The so-called 'favelas' of Brazil house more than 11 million individuals in marginalised areas [4].

Emphasising the social and urban issues that slum living represents to the city's inhabitants, this research aims to study the potentials of implementing the concept of Participatory Development in slum upgrading strategies as a means of improving the current living conditions of slum dwellers in a sustainable and human-focused manner. During the research process, previous works on slum countermeasures worldwide were studied, and existing cases of PD strategies carried out in mostly Latin American slums were taken as a reference for comparative and evaluation purposes.

\section{CONTEXT: SLUM LIFE IN CARACAS}

Caracas suffers from severe environmental problems that are worsening because of rapid urbanisation. The city in the valley is surrounded by hillsides that are covered in ranchos (ghettos), makeshift housing and slums where poverty, crime, and desperation prevail. Not all slums are the same in terms of size, infrastructure, and even social status - some slums house individuals with stable jobs, decent education, and provide an acceptable level of material comfort, while others shelter people with informal or no jobs, and lack vital services and acceptable standards of living. According to statistics and a cartographic analysis in the slums of Caracas, findings reveal that over half of the capital's population is currently residing in informal settlements, where housing density is 3 to 4 times greater than that of planned areas. This is due to the rapid urbanisation process in slums, which doubles that of formal segments of the city. Between 1966 and 2014, slum areas were quadrupled from $13.5 \mathrm{~km}^{2}$ to $43.3 \mathrm{~km}^{2}$, whereas formal urban areas only doubled from $63.7 \mathrm{~km}^{2}$ to $135.7 \mathrm{~km}^{2}$ [5].

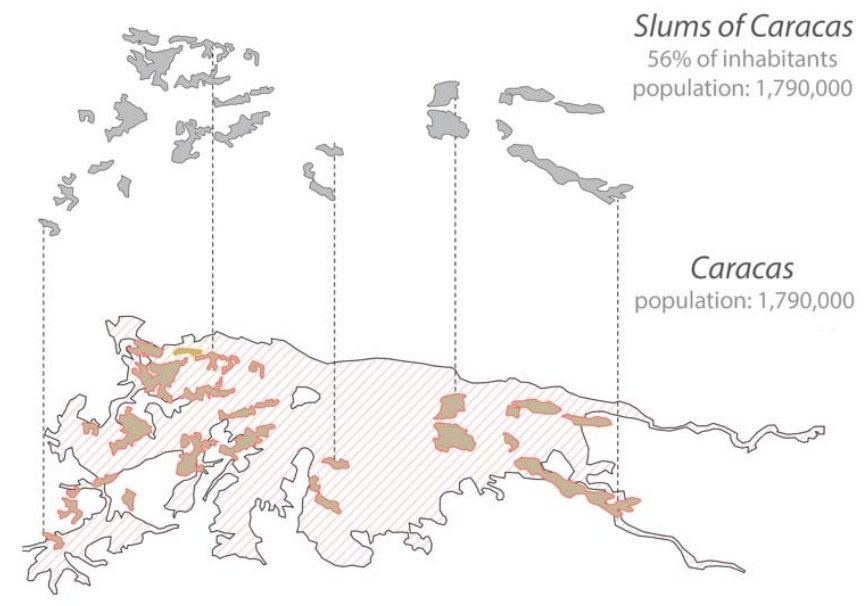

Figure 1: Map of Caracas showing slums and percentage of inhabitants. 
From an environmental, public health, and safety point of view, binge slum housing construction on irregular hillside terrains with no professional architectural or engineering management, and no consideration for the natural environment, not only damages the land, as no studies on soils and rocks are carried out (leading to perilous earth movements and potential landslides during the rainy season) [6], but it additionally puts people at a greater risk of contracting gastrointestinal, mycotic, and respiratory diseases [7]. Poor sanitation, accumulated waste, and close living quarters mean that sickness becomes endemic in slum living; infections spread easily and, in the case of Caracas and its hillside slum locations, access to healthcare is distant and inconvenient.

With regard to safety, we do not only refer to appropriate health standards and welfare, but also to the security hazards that slum living represents to its inhabitants. According to multiple sources, Caracas has been described as the most dangerous city in the world to live in, with a homicide rate of 119.87 per 100,000 residents [8]. This rate that has quickly escalated over the years, and that continues to top every other city in the world as the situation in the country worsens, and distress increases. It is said that crime and violence in Caracas sprawls from its barrios and spreads over other areas of the city, and so to live in the very core of this anarchy, greatly imperils the citizens' lives and well-being. According to a survey conducted by the Bank of Development of Latin America (CAF), also responsible for the aforementioned "Inclusión de Habitantes" project proposal, almost $20 \%$ of all causes of death in the 'El Morán' slum were homicides - this is an alarmingly high number, especially when one becomes aware that this is not even considered to be one of the most dangerous districts in Caracas [9]. The causes of crime worldwide are complex, but poor parenting, deprived education, and economic conditions (unemployment) are well known to be decisive factors.

An interesting article published by 'El Universal' journal in Venezuela, describes Caracas as two cities that make up one city:

In the first one, all the economic activities of the city and a significant part of the whole country are carried out, and its inhabitants, generally speaking, have relative economic affluence. It is possible to live in it with certain comfort. The second one, only allows its inhabitants to perilously 'occupy' the land, with limited or scarce road access... in the majority of cases, basic services do not suffice to provide a mininum level of comfort. There, poverty and extreme poverty prevail. Its inhabitants are mostly low-cast workers, who work in the first (city) and sleep in the second. The inhabitants of the first do not visit the second, and do not need to do so either... [10].

Slums in Caracas are, without doubt, marginalised areas of the city; areas that have been too long-ignored and deprived of any form of human decency, as have their people. Slum dwellers lack, in many cases, the opportunities to succeed and improve their living conditions, resulting, generation after generation, in repetitive cycles of poverty and marginalization. When we set aside the issues linked to the great social, economic, and geographical divide between these "two cities", we begin to recognise cultural elements of their own; slum living is not inevitably about violence and insalubrity, there is also a cultural manifestation that is represented through their use of language, clothing, music, street art, and other elements that shape their identity and heritage.

\section{COUNTERMEASURES}

There is not a single answer to all the complex questions posed by the slum challenge. Not all slums possess the same characteristics and difficulties and will therefore, require different solutions and countermeasures; for instance, slum removal, slum upgrading, and slum relocation. All three of the aforementioned countermeasures have been studied and proposed 
by different groups of professionals in Venezuela, and their benefits and drawbacks can be analysed [11].

To better understand the results and consequences of these countermeasures on a larger scale, we have taken redevelopment projects in other countries as reference for this research.

\subsection{Slum removal and slum relocation}

This strategy has been utilised by some advanced nations such as China (Beijing 2008), the US (Housing Act 1949), and the UK (Slum Clearance Act 1955), where the aim has been to remove the slightest trace of poverty from well developed areas of the country. One remarkable example is the 2008 Summer Olympics in Beijing, where 1.5 million people were forcibly evicted, and densely populated neighbourhoods were torn down to make way for new infrastructure projects [12]. In this case, the welfare of the better off, including local residents or tourists and spectators, was deemed more important and prioritised at the expense of the well-being and stability of the evictees. From an architectural point of view, the infrastructure of the city was indeed improved by this massive redevelopment, as other aspects of the city's components, such as public transportation and public spaces were also reconditioned alongside it. Slum removal tends to be utilised as a long-term countermeasure to rehabilitate and upgrade an urban area, yet in the case of Beijing, it completely neglected the human and housing rights of the slum occupants.

Given the social and economic state of Venezuela (more specifically Caracas), to opt for a plan similar to that in Beijing, would only temporarily "solve" the slum issue, given that it would ignore and bypass the root causes and actual social problems that generate slums in the first place, as well as depriving the citizens of their "illegal" rights to their land.

One slum relocation plan to take into account is that proposed by civil engineer Armando Scannone on his paper: "Barrios in Caracas as a human problem" [13], where he suggests a long-term plan to reinvent the city and its slums in the following manner:

- Assign spots inside and outside the city to relocate slum districts. This is done in stages to ensure lasting households, sanitation, and the project's feasibility.

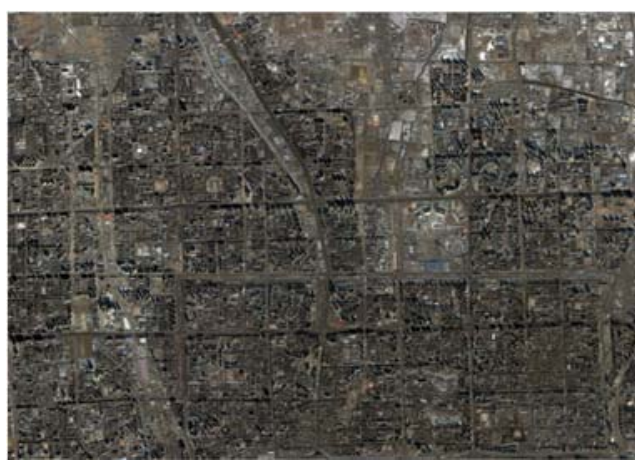

Figure 2: Aerial view comparison of Beijing Olympic Park area 2001.

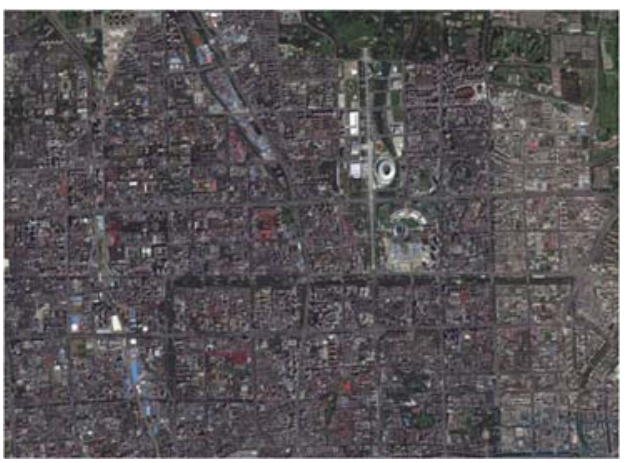

Figure 3: Aerial view comparison of Beijing Olympic Park area 2017. 
- Grant evictees compensation for their current homes, which they would use as down payment for their new upgraded residence (the state would provide loans and subsidise housing prices).

- As households are translated, empty plots will start emerging in the former slum areas, which would then be used for new redevelopment projects.

- Completely integrate the new relocated "slum" areas to the city with proper road access and public transportation, thus creating a sense of unity - "one single city".

While sounding ideal and perhaps even logical, those projects disregard one fundamental feature: the human aspect. It overlooks decades of slum culture and family bonding created in these slums. Venezuelan barrios, like any other district in the city, have a history, their own culture, and create an emotional attachment in those who reside in it. By completely relocating slums and their people to newer high-rise housing blocks or entirely residential areas, we interfere with their commercial activities (at times their only source of income), social relations, and sense of belonging.

\subsection{Slum upgrading}

British architect John F. C. Turner (1972) argues in his book: "Freedom to Build" theoretical strategies to solve the problem of slums. There, he opposes the general idea of slum removal, and suggests fixing components of the area instead. By providing clean water, good pedestrian and road access, as well as basic services, we are able to gradually improve the conditions of the slums [14]. Following this tendency, many countries have shifted policies towards slum upgrading strategies; several of them have achieved good outcomes and have therefore, provided moderate reduction or stabilization of slum growth rates. A study by the Inter-American Development Bank (2013) reviewed empirical evidence of the results of different slum upgrading programs, which lead to three groups of outcomes:

1. Housing outcomes (housing investments by owners, increases in housing values, access to credit, access to housing infrastructure, ownership and titling, household density, etc.);

2. Neighbourhood outcomes (improvements in urban services, impacts on security and violence, and social and urban integration);

3. Individual outcomes (income gains, health improvements, human capital, child development, labour market insertion, etc.) [15].

To this day, there are many examples where slum upgrading policies have led to positive outcomes; in Latin America, more specifically Colombia, these policies have been implemented as strategies to combat poverty and ensure an improved life quality, where an estimated 3.7 million slum occupants have benefited from well targeted strategies [16]. In Medellin, art, music, and culture, combined with the strategies of slum upgrading, have transformed a scene of violence into one of peaceful social coexistence and touristic attraction. This was a project that not only reconditioned the urban environment, but it also granted the youth and local artists in these neighbourhoods, the opportunity to reinvent their lives and move away from their violent past [17]. A similar case can be observed in Busan, South Korea, where the Gamcheon Village, previously one of the city's poorest shanty areas, was restored and enhanced in 2009 after the Ministry of Culture, Sports and Tourism decided to launch a project to model the village into a creative community [18]. The great advantage of these renovation plans is that they value and promote culture and heritage, sparking interest in the eyes of tourists who directly profit the area's economic growth. 


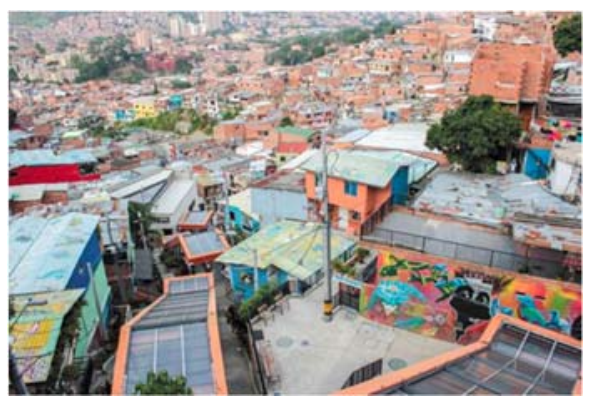

Figure 4: Slums of Medellín.

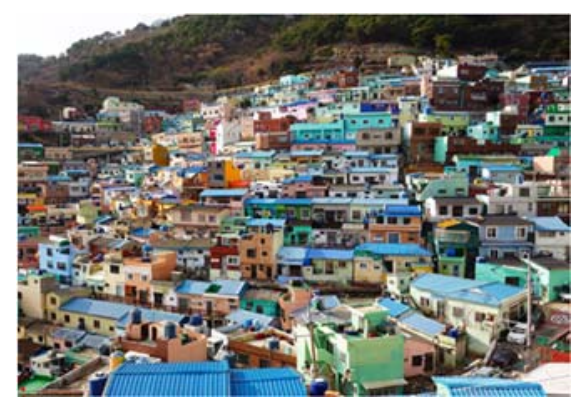

Figure 5: Gamcheon Village after restoration.

Currently, there exists a handful of project proposals that aim to alleviate the precarious conditions of slums in Caracas by implementing upgrading strategies. An academic assignment at the Central University of Venezuela, for instance, proposed an urban renovation plan at the 'Mamera III' slum in Caracas, where they projected large-scale changes by relocating households that were affected by an existing high-voltage network, and a ravine that cut across the ground, causing landslides throughout the rain season. After relocating these households to better-planned neighbourhoods within the same slum community, the former housing plots were cleared up and converted to a new pedestrian axis. This axis aims to create better accessibility throughout the sloped terrain by incorporating green terraces and sets of steps alongside well-designed public urban services and facilities, comprising urban furniture, as well as the construction of a series of interconnected open public spaces [19].

It should be noted, that slum upgrading projects have produced mixed results, and that despite good intentions, some slums have taken a turn for the worse. The causes of these setbacks are usually related to the projects' poor management, where the estimated costs were higher than expected, and the projects' completion deadlines were long overdue. Most slums in the world are located in developing countries, where there are oftentimes conflicting politics and corruption, and where the welfare of the communities might not always be a priority on the government's agenda. In the cases of Indonesia (kampungs of Jakarta) and the Philippines (Manila), the projects' management incorrectly addressed the causes of poverty, informal economy and other characteristics of slums, causing the slums in question to return to conditions worse than before [20].

Although controversial, it could also be said that similarly to the case of many developing countries, corruption and political instability are rife in Venezuela, so one could conclude that an attempt of slum upgrading in Caracas would lead to similar results as in the case of Indonesia and the Philippines. As a matter of fact, this is possibly true; if corruption continues to plague Latin American countries, and if their governments do not focus their policies on their citizens and their prospects for improvement, neither slum removal strategies, nor upgrading ones will ever solve the persistent issues posed by urban poverty in squatter settlements. If we are to propose upgrading strategies in informal communities of Caracas, we need to understand that these long-term plans require the full commitment of the government, as well as proper financial support to cover a broad range of expenses incurred by this massive-scale redevelopment. 


\section{PARTICIPATORY DEVELOPMENT AND DESIGN}

After being brought up as a concept in the 1970s, Participatory Development or PD was given various different interpretations as years passed, meaning that there is no universal definition of PD. Theorists agree that participation is "a process by which people, especially disadvantaged people, influence decisions that affect them" as an alternative to having external entities impose decisions for them [21]. It refers to the involvement of the local populace in the creation, content, and management of policies devised to influence their lives. Participation requires the recognition and employment of local experience, avoiding the imposition of priorities foreign to the site, thus increasing the likelihood that these policies and programmes accomplish their original goals and that the results are sustainable.

Participatory Development is fundamentally about a more balanced distribution of power in terms of decision making. In theory, this allows for processes to run more smoothly, as people work better around problems that involve them, leading to improved economic decision, time management, and more open-ended trajectories. This might sound ideal when projecting "for the people", although in practice, the concept of PD is sometimes cunningly adopted by big enterprises as means of displaying concern for the locals' opinion, while having a preconceived agenda and interests of their own.

In Latin America, PD strategies are currently being tested in a small number of proposals by emerging countries. In Peru, the concept of PD was implemented in a workshop titled "Resilient Barrios Altos", in which five shanty houses of the 'Barrios Altos' slum in Lima were subject to intervention. More than an architectural project per se, the workshop stimulated communication between the residents about important topics of public relevance, with the goal of finding common ground amongst the many different points of view in the local community. This ultimately led to solutions that were compatible with their social, cultural, and economical reality. The success of the workshop lies in this, that both the participants (architects) and the residents were forced to think outside the box in order to find innovative ways of feasibly gathering and managing the money, restoring the existing structures, and constructing newer ones [22].

A group of architects in Colombia have also applied the same methodology to recover ' $\mathrm{El}$ Trébol', once a community space that was abandoned by the neighbourhood due to lack of maintenance. The redevelopment of this space, located in the 'Kennedy' slum in Bogota, intends to create a community space where meeting for workshops, concerts, projects and expositions can be held, and where expressions of the inhabitants' own slum culture can be manifested in the form of literature, dance, music, skating, and art [23].

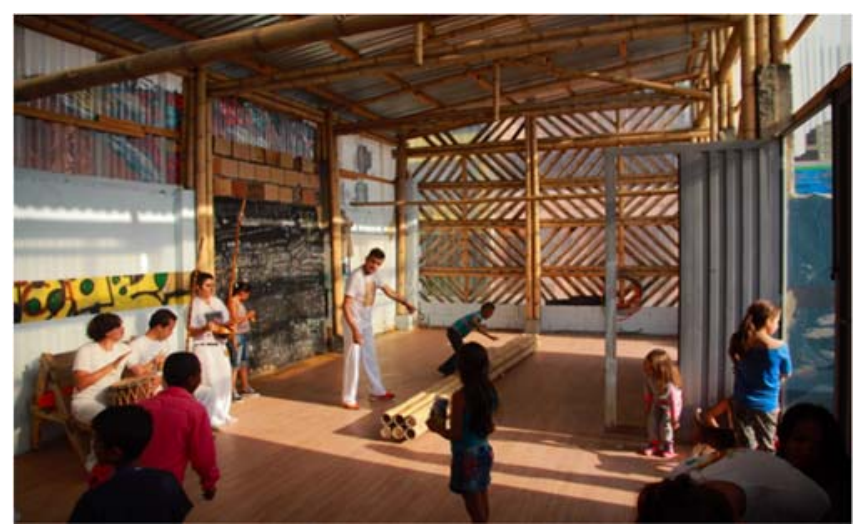

Figure 6: 'El Trébol' community centre after its restoration. 
Despite the fact that most slum rehabilitation plans in Venezuela end up as purely academic proposals, smaller scale intervention projects have managed to positively affect the lives of a wide range of communities in different regions of the country. Some social-aimed projects like 'Espacios de Paz' have proposed to refurnish and improve urban areas in informal settlements in the slums of Caracas where urban planning is absent and quality of life improvement solutions are scarce. This project is turning areas of danger into areas of peace by endorsing Participatory Design strategies with the aim of developing public spaces with the aid of the residents. So far, they have managed to complete a handful of projects utilising only local resources, for example, sport courts, observation decks, playgrounds for children, and other forms of leisure spaces that can be enjoyed by the whole community.

In light of the inadequate access to construction materials in the country, the developers made the decision to construct with four very simple materials at their disposal: steel, concrete, wood, and plastic. Their methodology was "to integrate the locals through work" by recruiting them as helpers with no former building experience, encouraging them to participate in the execution of the projects, eventually turning them into skilled construction workers and carpenters [24].

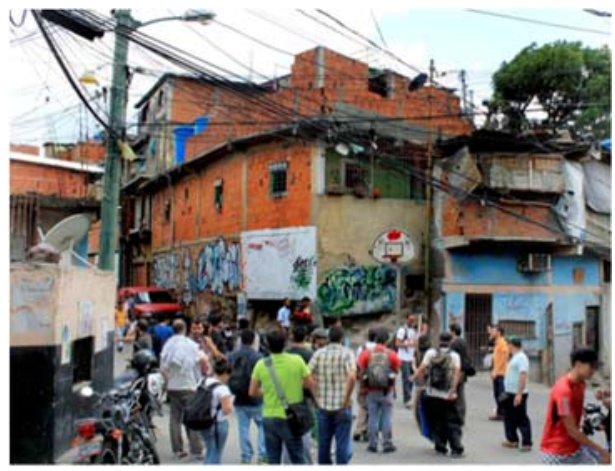

Figure 7: 'Espacios de Paz', before. Comparison after PD implementation in a slum of Caracas.

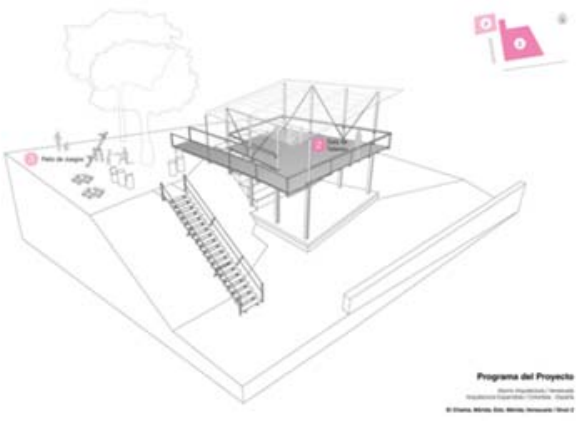

Figure 9: 'Espacios de Paz' Isometric view of Gazebo.

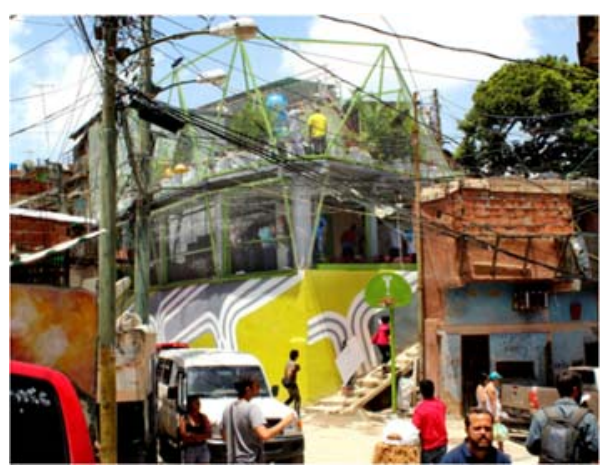

Figure 8: 'Espacios de Paz', after. Comparison after PD implementation in a slum of Caracas.

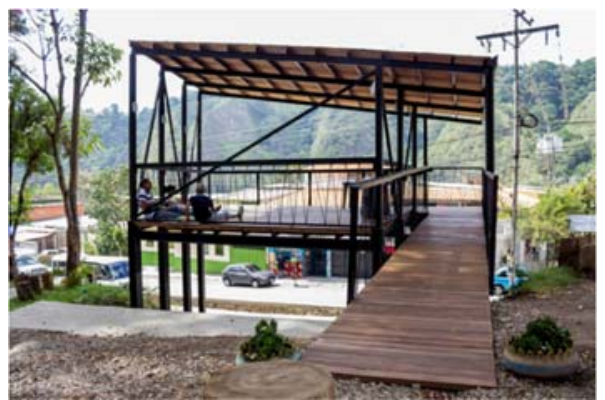

Figure 10: 'Espacios de Paz' completed project in Merida city, Venezuela. 


\section{CONCLUSION}

In architectural proposals, unlike perhaps some other areas of design, PD allows for people to not only participate in the brainstorming and decision-making processes, but in the construction phase of the project as well. From a psychological point of view, this grants those living in poor conditions the sense and certainty that their ideas and opinions are being taken into account, especially important since the outcome of any attempt at slum rehabilitation would massively influence their lives and their future, whether positively or negatively. It challenges the general idea that outsiders with professional experience know better and must therefore impose their foreign ideals on already established communities. Professionals (architects, engineers, planners, etc.) on the other hand, must serve as advisors or guides who understand the situation and its technicalities in a general context, and who have a good grasp of the tools and methods that could be employed to better lead the development of the project.

To instigate discussion allows people to bring attention to silenced voices, where there was perhaps no space to do so before in an organised fashion. It creates a sense of empathy, not only between the residents who may share similar issues in their daily lives, but also among professionals, who as outsiders, cannot fully comprehend the difficulties these people must endure. Planners must use the knowledge acquired from the residents (their needs, desires, concerns...) as a guide to direct the course of the intervention proposal, applying their own professional judgment to guarantee not only the locals' satisfaction and well-being, but also the project's appropriate development.

In the specific case of slums, applying PD strategies to involve the community in the construction processes of the project may lead to even greater results than simply incorporating the residents' ideas into the project by teaching them the value of the work through participation. John Turner (1972) advocates the idea that "user-controlled housing (when it is also materially economic) is far superior as a vehicle of personal, family, and social growth or development than housing which is merely supplied" [25].

By being deeply involved in these processes, they are able to quickly pick up new skills, obtain a better understanding of money and time management, develop a sense of responsibility, and foster respect among their fellow slum dwellers. Therein lies the constructive potential of Participatory Development, in that it recognises that the deep-seated issue of slums requires a process of gradual change, and that this change must start from the people who reside in these settlements; PD acknowledges the human aspect in slum living and fosters residents' own capacity for improvement, not simply in a technical, architectural sense, but also, vitally, on a personal and social level.

\section{REFERENCES}

[1] Klepsch, L., A Critical Analysis of Slum Tours: Comparing the Existing Offer in South Africa, Brazil, India and Kenya, pp. 9-11, 2009-2010.

[2] UN - Habitat for a better urban future. Housing and Slum Upgrading, Online. https://unhabitat.org/urban-themes/ housing-slum-upgrading/

[3] UN - Habitat. 24 ${ }^{\text {th }}$ Session Governing Council, Nairobi, pp. 2-3, 2013.

[4] Mangin, W., Latin American Squatter Settlements: A Problem and a Solution. Latin American Research Review, 2(3), pp. 65-98, 1967.

[5] Silva, E., Mapping of the slums of Caracas, 2016, Online. http://prodavinci.com /2016/06/17/ciudad/mapeo-de-los-barrios-de-caracas-por-elisa-silva/ (in Spanish).

[6] Genatios, C.V., From risk to disaster, pp. 1-2, 2012 (in Spanish). 
[7] Effects of the incorrect management of solid waste, 2015, Online. http:// gestionmanejodesechossolidos.blogspot.jp/2015/03/efectos-que-causan-el-manejoincorrecto_6.html (in Spanish).

[8] World Atlas, most dangerous cities in the world, 2017, Online. http://www.worldatlas.com /articles/most-dangerous-cities-in-the-world.html

[9] CAF, Bank of Development of Latin America. Inclusión de habitantes en la ciudadanía plena, pp. 41-42, 2013.

[10] Scannone, A., Los barrios en Caracas como problema humano. El Universal Journal, Venezuela, 2016.

[11] Blog containing various slum intervention proposals, Online. http://www.skyscrapercity.com/showthread.php?t=1283423

[12] COHRE, One World, Whose Dream? Housing rights violations and the Beijing Olympic games, pp. 6-9, 2008.

[13] Scannone, A., Los barrios en Caracas como problema humano. El Universal Journal, Venezuela, 2016.

[14] Turner, J.F.C. \& Fichter, R., Freedom to Build, Macmillan: New York, 1972.

[15] Jaitman, L. \& Brakarz, J., Evaluation of Slum Upgrading Programs, literature review and methodological approaches, pp. 5-6, 2013.

[16] Torres, C., Ricon, J. \& Vargas, J., Pobreza urbana y mejoramiento integral de barrios de Bogotá, pp. 19-31, 2009 (in Spanish).

[17] Polanco, D., Turismo en barrios de Medellín. Listin Diario Journal, Colombia, 2016. (in Spanish)

[18] History in the hills: Busan's Gamcheon Culture Village, 2013, Online. http://busanhaps.com/history-hills-busans-gamcheon-culture-village/.

[19] Proyecto de renovación urbana, Mamera III, Urban Design Master Thesis at the Central University of Venezuela, 2009, Online. $\mathrm{http}: / /$ transgresionesurbanoarquitectonicas.blogspot. $\mathrm{jp} / 2012 / 05 /$ proyecto-de-renovacion-urbana-mamera.html (in Spanish).

[20] Kessides, C., World Bank Experience with the Provision of Infrastructure Services for the Urban Poor: Preliminary Identification and Review of Best Practices, 1997.

[21] Giles, M., Participatory Development, pp. 1-11, 2001.

[22] Clima Sin Riesgo, Barrios Altos: Viviendo en riesgo en el centro histórico de Lima, 2015, Online. http://www.climasinriesgo.net/news-summer-workshop-resilientbarrios-altos-begins/?lang=es (in Spanish).

[23] Colectivo Arquitectura Extendida, El Trébol de Ciudad de Cali, 2015, Online. http://arquitecturaexpandida.org/category/proyectos/ (in Spanish).

[24] PICO Colectivo, Espacios de Paz, 2014, Online. http://picocolectivo.org.ve/page/2/

[25] Turner, J., Housing as a verb. J.F.C. Turner \& R. Fichter (eds.), Freedom to build, pp. 148-175, 1972. 